\title{
Dominique Kalifa \\ (1957-2020)
}

"Estudia el delito de Belle Époque, los bajos fondos. Y preside una sociedad de amigos de Fantômas." Tales los primeros datos sobre Dominique Kalifa que me ofrecía un colega, hace muchos años ya, antes de internet y las sendas trazadas por algoritmos. Lo menos que podría decirse es que no éramos muchos los que transitábamos esos temas en aquel momento, así que el dato -ofrecido como quien comparte una rareza- fue apreciado en su justa medida. Un perfil que combinaba la apuesta al mundo del crimen como tema de la historia y el liderazgo del club de fans de un héroe maldito de la cultura popular del 900 plantaba de por sí el germen de la curiosidad.

No hacía falta más. La descripción impulsó la búsqueda precipitada, y esa búsqueda el hallazgo de un primer libro, que resultó ser también el primero de una obra vasta y personalísima. Un trabajo de escala mayor, además, que desde la primera ojeada revelaba síntomas de calidad. L'encre et le sang. Récits de crime et société à la Belle Époque (Fayard, $1995)$ era fruto de una tesis doctoral escrita en la Universidad de Paris-Jussieu bajo la dirección de Michelle Perrot, y defendida apenas el año previo a esa publicación en una editorial mayor. Recuerda esta historiadora, profesora y maestra del joven Kalifa, la nitidez precoz de sus intereses, la seguridad en el rumbo de aquel primer proyecto, rasgos que llegaban junto al aire vagamente provocador de su sonrisa, y detalles de apariencia que sugerían cierto gesto de resistencia a las discretísimas reglas vestimentarias de la academia. ${ }^{1}$

\footnotetext{
1 "Hommage à l'historien Dominique Kalifa", Le cours de l'histoire, 18 de septiembre de 2020, Radio France Culture. Disponible en <https://www.france culture.fr/emissions/ le-cours-de-lhistoire/a-lhistorien-dominique-kalifa $>$.
}

Desde el principio fue claro que no era el estudio estructural de la prisión o el crimen lo que más interesaba a este nuevo investigador. Se trataba más bien de interrogar las vías de acceso a esos mundos, los relatos que los representaban, aquellos destinados a las grandes mayorías. Tal sería su campo de exploración, definido con audacia en disputa abierta con Roland Barthes, y los análisis estructuralistas (ahistóricos) del faits divers. La prueba del valor heurístico de materiales largamente despreciados, como los reportes policiales de prensa y las crónicas del submundo delictivo, tendría el efecto de una potente renovación, una suerte de detonante que a partir de entonces iría desplegando sus vertientes.

Los años siguientes verían el desarrollo de una vasta agenda: ensayos sobre delito y cultura (Crime et culture au XIX siècle, Perrin, 2005); estudios sobre los detectives privados parisinos (Naissance de la pólice privée: Détectives et agences de recherche en France, Plon, 2000); sobre la prisión colonial (Biribí. Les bagnes coloniaux de l'armée française, Perrin, 2009); sobre la policía urbana (Le commissaire de police au XIX siècle, codirigida con P. Karila-Cohen, Ed. de la Sorbonne, 2000); sobre la investigación judicial (L'enquête judiciaire en Europe au XIXe siècle, codirigida con Jean-Luc Noël y Jean-Claude Farcy, Créaphis, 2007), entre otros. Sin duda, estos títulos resonaban con los que iban surgiendo del desarrollo de un campo específico de historia de las fuerzas de seguridad. Pero el vistazo más distraído a los sesgos y tonalidades de ese recorrido marca una diferencia inmediata. Incluso los estudios anclados en el repertorio temático más tradicional (la prisión, la justicia, la policía) insinuaban el potencial de irradiación en otras direcciones. En 
el universo historiográfico de Kalifa, el interés último en ese mundo radicaba en las posibilidades que se abrían hacia los imaginarios urbanos, un objeto que abarcaba las vías mismas de construcción de esos universos, como el periodismo, la prensa, las culturas de masas. Inscripta desde el principio en el corazón de la empresa, esta inquietud marcaría el carácter de toda la obra, su expansión a la vez variada y coherente.

Así, aquel historiador asociado a los imaginarios del delito demostró ser un promotor fundamental de la historia de la prensa y la cultura masiva. Entrelazados con sus obras más identificatorias estaban, en efecto, su breve La culture de masse en France (La Découverte, 2001) y, sobre todo, el monumental La civilisation du journal. Histoire culturelle et littéraire de la presse française au XIX siècle (Nouveau Monde, 2011), un volumen colectivo de más de 1700 páginas, codirigido con Marie-Ève Thérenty, Alain Vaillant y Philippe Régnier. Punto de llegada de numerosas investigaciones, el proyecto insinuaba desde su mismo título una aproximación distanciada de los usos más tradicionales del diario como fuente de la historia. El recorrido que trazaba el índice, y la densa introducción programática, establecían el poder simbólico estructurante de los diarios decimonónicos, sus intersecciones urbanas, su carácter de máquina de imaginarios colectivos. Historia "cultural" y "literaria" del diario: una aproximación tramada por la inquietud por las sensibilidades, la sociología de la producción y la lectura, cierta inflexión antropológica en el estudio de los consumos y fuertes afinidades con los aportes de la literatura.

En el febril ciclo productivo del Kalifa de los años 2000 figura Imaginaries et sensibilités: études pour Alain Corbin (Créaphis, 2005), un volumen colectivo coorganizado con Anne-Emmanuelle Demartini en honor de quien había sido su otro gran maestro. La influencia de Corbin -cuya cátedra de Histo- ria del siglo XIX en la Sorbona Kalifa heredaba en 2002- es perceptible a muchos niveles, en efecto, comenzando por el interés en el ejercicio de la reconstrucción-mosaico, y la aproximación más bien oblicua, a partir de figuras oscuras o inusuales, al abordaje de los imaginarios colectivos. No sin razón, muchos reconocen aquí el centro neurálgico de su obra. Los imaginarios de esa París de Belle Époque, reconstruidos a partir del cruce de archivos de prensa y literatura de gran circulación, eran el núcleo que anudaba las tantas inflexiones parciales -hacia el delito, hacia la prensa y la literatura, hacia la ciudad-.

Es un testimonio del cruce de estas genealogías con las búsquedas del propio Kalifa -y de un camino singular en el ámbito de la historiografía francesa- que uno de los estudios más ambiciosos de su fase madura volviera sobre la reconstrucción de los imaginarios del bajo fondo con recorridos que renovaban las perspectivas por él mismo establecidas años antes. Escrito durante una estancia en Inglaterra, Les basfonds. Histoire d'un imaginaire (Seuil, 2013) introducía un aliento transnacional (trans-urbano, más bien), y la pregunta por la circulación de ciertas estructuras sensibles. Y si bien París mantenía el lugar prominente (inevitable, por lo demás), esa cartografía era puesta en una perspectiva que reservaba un lugar genuino -en el argumento, no en la nota de compromiso- a los estudios sobre otras ciudades europeas, norteamericanas, y latinoamericanas también.

Además de exhibir sintonía con los vientos historiográficos, es posible ver allí los rastros de las derivas del Kalifa de esos años, profesor instalado en el corazón del sistema académico francés, a la vez que historiador de perfil internacional cada vez más conspicuo. Sacando provecho de un trilingüismo muy inhabitual entre sus compatriotas (hablaba perfectamente inglés y español), iría cultivando vínculos con colegas en universidades de todo el mundo, multiplicando visitas a los Estados 
Unidos, España, el Japón, Inglaterra, México y el Brasil, un movimiento en paralelo con el inicio de un ciclo de traducciones de su obra al inglés, el portugués y el español. En esos años, su seminario de la Sorbona devendría en escenario del paso de muchos profesores invitados, que hablaban con los acentos más diversos a una audiencia salpicada de estudiantes internacionales.

Es momento de volver sobre aquella alusión, en la primera recomendación de café, a la figura de Kalifa como promotor del héroe maldito Fantômas. Pues pronto fue evidente que no se trataba de un detalle, sino de otro síntoma de un compromiso con la historia que tenía mucho de entusiasmo y de audacia. "Kalifa was a joy ful historian", tal es el título de la evocación reciente de un colega norteamericano, Thomas Dodman. ${ }^{2}$ Muchos reconocíamos esa chispa. Ni la hiperproductividad, ni la centralidad creciente en un campo tramado de hitos y reglas seculares, ni el peso aplastante de la gestión: nada de eso parecía disolver cierto sentido lúdico de las cosas. El poder académico ganado -el acceso a subsidios y viajes, los vínculos editoriales, las conexiones de ultramar- era puesto al servicio de empresas que mantenían vivo ese elemento de aventura y goce intelectual.

El gesto de libertad implícito en la promoción de un personaje ficticio que habitaba sus archivos era mucho más que una marca de apego juvenil, en efecto, como lo muestra la persistencia de este compromiso a través de las fases de laboriosa construcción de un lugar en la disciplina, y más allá (Tu entreras dans le siècle en lisant Fantômas, Vendemiaire, 2017). En ese camino, otra deriva tocaba a la experimentación en los formatos, a las preguntas por las poéticas de la historia, a la exploración de sus posibilidades. La per-

\footnotetext{
${ }^{2}$ En $<$ https://frenchculture.org/books-and-ideas/12278dominique-kalifa-was-joyful-historian $>$.
}

durable asociación con Philippe Artières -la figura de su generación que más intensamente apostaba al estudio de las prácticas de la escritura y los personajes en los bordes- dio por resultado Vidal, le tueur de femmes (Verdier, 2001), la biografía de un asesino del 900 escrita a partir de multitud de rastros dispersos. A esto seguiría el proyecto conjunto "Histoire et archives de soi", un dossier-libro sobre los archivos personales como materia de la historia, publicado en Sociétés \& Représentations (CREDHESS, 2002). Luego, en 2008, Artières y Kalifa se unían a SylvainVenaire, Stéphane Michonneau y Anne-Emmanuelle Demartini en torno a una empresa planteada al límite del divertimento. Un dossier hallado por Artières en una feria de objetos usados fue distribuido entre los cinco, y cada uno invitado a escribir veinte páginas sobre el personaje al que referían los documentos - un tal Bertrand- sin comunicarse con los demás. De ese ejercicio, tramado de reglas al estilo Oulipo, nacía $L e$ dossier Bertrand. Jeux d'histoire (Manuella, 2008), un perfil hecho como un collage, a partir de las miradas cruzadas de los cinco participantes. Ejercicio-juego, el libro reivindicaba el deseo como motor de la escritura de la historia, a la vez que ponía en evidencia la naturaleza epistemológica de ese producto (confrontando métodos en torno a un mismo corpus), y también su dimensión poética (poniendo en evidencia el carácter textual de toda narrativa sobre el pasado). Cuenta Venaire que Kalifa organizó para la ocasión un encuentro en el Centro de Estudios del siglo XIX, que dirigía, y que los recibió vestido con un deslumbrante traje blanco, acompañando la aventura con uno de esos despliegues de elegancia dandy, propio de su paleta de gestos a la vez elegantes y humorosos. ${ }^{3}$

${ }^{3}$ Sylvain Venaire, "Dominique Kalifa est mort", L'Histoire, 14 de septiembre de 2020. 
Que semejante repertorio de intervenciones en la arena académica conviviera con veinte años ininterrumpidos de colaboración como reseñista de libros en el diario Libération, y que esa participación se extendiera luego a Twitter, en una cuenta personal que difundía actividades, lecturas y entusiasmos muy diversos: todo eso habla de la fidelidad a ciertos gustos, y también de la opción por circulaciones que excedían las vías más predecibles de la profesión. Incluso dentro del universo disciplinar, es notable que la vasta obra producida en esos años no encontrara su forma de expresión principal en la proliferación de artículos en revistas académicas internacionales, sino en la publicación de libros, un formato más tradicional, de circulación más abierta e indeterminada. Cómo no decir, por fin, lo más evidente: que este alcance de registros hablaba a gritos de una capacidad de trabajo del todo extraordinaria -en la lectura, no menos que en la investigación y en la escritura-. Y que este rasgo era más notable por no ser nunca enfatizado en la conversación, ni puesto en escena como tal, dejando que se revelase en sus frutos, evitando el gesto autosacrificado de historiador industrial.

Este Dominique Kalifa es el que vendría a Buenos Aires en 2017, en una visita largamente prometida. Para entonces, éramos viejos conocidos. La lectura de su obra temprana había impulsado las primeras reseñas, seguidas de intercambios de mail, y muy rápidamente, de las primeras invitaciones. La relación con los colegas brasileños, argentinos y mexicanos fue larga y fructífera. Kalifa (Dominique) atribuía risueñamente su cultivo de estos vínculos a un cosmopolitismo difuso ligado a sus orígenes sefaradíes, en este caso facilitado por su manejo del español obtenido en una estadía de juventud en Panamá. Por nuestro lado, las razones para interesarnos apenas necesitan explicación. El acceso a su obra había transcurrido en pleno desarrollo de importantes campos de estudio de la cuestión criminal en la región. No tardó su trabajo en ganarse un lugar de referencia, sobre todo entre quienes estábamos interesados en las posibilidades de acceso, por la vía de las narrativas del delito, a los problemas de la cultura urbana. Habíamos encontrado un referente, que quería ser un aliado, que muy pronto era un amigo.

Entusiasta como siempre, traía bajo el brazo su nuevo libro, La véritable histoire de la "Belle Époque" (Fayard, 2017), un título que evocaba el territorio que ya era familiar a quienes conocíamos su obra, pero marcaba en verdad el inicio de un proyecto de largo aliento. Se proponía allí el estudio de los “cronónimos", los nombres de época. Y se ponía la etiqueta "Belle Époque" al servicio de una reconstrucción que abordaba las resignificaciones de esa expresión a lo largo de todo un siglo. Ya estaba en marcha, a esas alturas, la gran empresa subyacente, un volumen colectivo bajo su dirección que exploraba los casos de mayor impronta en los imaginarios colectivos (Les noms d'époque. De "Restauration" à “années de plomb”, Gallimard, 2020). Se abría una cantera de proporciones, con subproductos y discusiones por delante. Nada menos parecido a una obra final.

Colegas de todo el mundo han evocado a Dominique Kalifa en los últimos meses, echando mano como han podido de alternativas a la expresión directa de la emoción. Unas importantes jornadas en su homenaje se preparan en la Sorbona, su hogar académico, para fines de este año. El tiempo empieza a pasar, y con él aparecen las vías más sosegadas del balance historiográfico. Agradezco la invitación de Prismas a escribir estas líneas, buscadas en los únicos lugares posibles: en las derivas de esa obra desbordante de posibilidad, y en lo que nos mostró una manera a la vez comprometida, lúcida e imaginativa de habitar la historia.

\section{Lila Caimari}

Universidad de San Andrés / CONICET 